\title{
IoT based Smart Vehicles for Fuel Consumption
}

\author{
Gauri A. Patil \\ BE Comp \\ Sandip Institute of Engineering \\ and Management
}

\author{
Gayatri A. Patil \\ BE Comp \\ Sandip Institute of Engineering \\ and Management
}

\author{
Priyanka S. Sangle \\ BE Comp \\ Sandip Institute of Engineering \\ and Management
}

\author{
M. V. Korade \\ Sandip Institute of Engineering and Management \\ Savitribai Phule Pune University
}

\begin{abstract}
In today's world, actual record of fuel filled and fuel consumption in vehicles is not maintained. It results in a financial loss. To avoid this we are implementing for sensing the amount of fuel filled in the vehicle. So as soon as agent starts filling petrol in your bike/car, using the Loadcell. The basic Objective of this project is to know exact amount of the petrol remaining in the fuel tank and how much distance it can travel. Also we can find near by petrol pumps and also it will indicate that the petrol pumps are out of petrol or not.The graphical display will show how much fuel is there and how much was added as well and total amount of fuel in the fuel tank this will be evidence of any kind of cheating is done by the ones fillings the fuel. this will nearly eradicate any kind of tricks pulled off by the petrol pumps. This flow sensor will be active till flow ends. Once flow ends it will calculate the amount of fuel filled and directly notify on your Dashboard an IOT fuel monitoring system and the Many a times while travelling, people get stuck in the middle of nowhere due to an empty fuel tank. Our project aims at eliminating this problem by searching and showing the nearest petrol pump to the user. We have developed an android application will notify us whenever petrol will go lower than particular level that the vehicle can travel how much $\mathrm{km}$ or distance in that petrol and it will also indicate the nearby petrol pumps and the petrol pumps are out of petrol or not. previously the vehicles have traditional fuel indicator meter that show the petrol level but the accuracy was not there so this system will give us the accuracy. To stop the frauds at the petrol pumps. To improve the accuracy in the petrol measurement .To reduce the amount of time to for finding the nearby petrol pumps.
\end{abstract}

\section{General Terms}

Your general terms must be any term which can be used for general classification of the submitted material such as Pattern Recognition, Security, Algorithms et. al.

\section{Keywords}

Sensors and Actuator, location based Services, software prototyping, database web servers.

\section{INTRODUCTION}

The Equipment, such as cars, motorcycles, trucks, generators, and compressors, which is powered by internal combustion engine needs a means of refueling so that it can run for as long and efficiently as possible. The problems associated with this equipment are to know how to contain fuel, to know how much fuel is left, and to know how best the fuel should be stored for users' safety, security, and benefits Presently most of the motor vehicles display the amount of fuel in the fuel tank with the help of some or the other kind of indication showing the $\mathrm{E}$ (empty), $\mathrm{H}$ (half) and $\mathrm{F}$ (full) indicators. The manufacturer provides the specification that $\mathrm{E}, \mathrm{H}$ and $\mathrm{F}$ bar maps corresponding to the liters of fuel approximately. In daily life we might have experienced the problem of improper measurements of the fuel level in the tank with the existing system. Today in this digitized world if the analog fuel indicators in the vehicles are replaced by 1digital system then it will help us to know the exact amount of fuel present in the tank. Currently the fuel indicator system for the most of the vehicles are analog and they do not show the exact amount of fuel present in the tank .So this problem is taken into consideration in this work for developing the digital fuel indicator system for two Wheeler's which shows exact amount of fuel in terms of milliliter. All internal combustion engines running on liquid fuel have to be very fuel efficient from economic point of view. All these engines are equipped with most advanced automated fuel indication devices. These are system built devices. There should be some provision at the user level to know the quantity of fuel at all times. The safety and security of fuel is of utmost importance. In the recent years, escalating oil demands and costs of fuel are increasing. This indirectly increases the overheads of many businesses and those with large vehicle fleets. Global oil supply and demand forecasts for 2015 have changed significantly recently, but these changes have largely cancelled each other out. The outlook is still one of a market roughly in balance. However, it is at times of rapid market change that forecasting becomes most difficult. In July of 2014, before crude prices collapsed, forecasts from the International Energy Agency, US Energy Information Administration and OPEC suggested that world oil demand would rise by about 1.35 million b/d in 2015 and that the global supply/demand balance would be very slightly positive. To cater the needs of fuel savings due to a one of the few above mentioned problems, the SIM 900 GSM module is used over a Global System for Mobile Communications (GSM) effective remote fuel-level monitoring system.

\section{EXISTING SYSTEM}

Existing system in the vehicle is traditional meter and that meter does not shows the exact amount of the fuel in the tank and due to this the cheating is happening on the petrol pump and customer are not happy and unsatisfied The measurements are taken so the accuracy level is of $95 \%$ $98 \%$. Thus it is an efficient device made by keeping in mind the petroleum thefts at the various petrol pumps at the time of filling of tanks. The existing traditional and the microcontroller based float type measurement techniques are far from exact and are on the conservative. The problem is also that we don't know exact fuel level so we forgot to fill the tank. The problems associated with this equipment are to 
know how to contain fuel, to know how much fuel is left, and to know how best the fuel should be stored for users' safety, security, and benefits Presently most of the motor vehicles display the amount of fuel in the fuel tank with the help of some or the other kind of indication showing the $\mathrm{E}$ (empty), $\mathrm{H}$ (half) and $\mathrm{F}$ (full) indicators. The manufacturer provides the specification that E,H and $\mathrm{F}$ bar maps corresponding to the liters of fuel approximately. In daily life we might have experienced the problem of improper measurements of the fuel level in the tank with the existing system. Today in this digitized world if the analog fuel indicators in the vehicles are replaced by 1digital system then it will help us to know the exact amount of fuel present in the tank. Currently the fuel indicator system for the most of the vehicles are analog and they do not show the exact amount of fuel present in the tank. So this problem is taken into consideration in this work for developing the digital fuel indicator system for two Wheeler's which shows exact amount of fuel in terms of milliliter.

\section{RELATED WORK}

With rising prices of oil, fuel theft has become a very common incidence. From economic point of view a system is devised that will take care of these practices. This system makes use of smart fuel theft detection with GSM alert and GPS tracking system. Using the ARM7 microcontroller, the real time position of vehicle and its fuel content is sent to owners mobile in case of intrusion. The system includes GPS module, Microcontroller, GSM module, LCD and a keypad. The GPS module transmits coordinates to the microcontroller that converts the data which is sent to the user in text format. This text message contains longitude and latitude of the location. This smart system gives $24 \times 7$ access to fuel consumption, alerts when fuel drains and storage tank leaks immediately identified. The user can access the quantity of fuel in the tank through this GSM and GPS technology. The keypad is unlocked using the secret password. A signal is sent for fuel verification. If fuel is beyond the range of the sensor the buzzer will go "on" for two minutes and simultaneously a text message is sent to the owner. The intruder can't stop the buzzer and if the buzzer is not stopped within two minutes then it will be treated as a theft of fuel and vehicle and a message is sent to the police station and to previously stored numbers with co-ordinates of that location. [1] The utilization of vehicles is rapidly increasing now a days and it leads to a huge problem of fuel availability. Often humans forgot to check the fuel level before taking vehicles and it will run out of fuel in half a way. All petrol and diesel filling bunks have digital displays to indicate the amount of fuel added. The users don't know whether it is showing the accurate value or not. To overcome this problem, this paper suggests a load cell based fuel measurement which gives exact level of fuel while fuel filling process and also in the travelling time. Nonstop monitoring of fuel level is attained by attaching the load cell below the fuel tank with the use of Arduino Uno and display unit fixed with dash board. The current speed of vehicle is indicated by the speedometer which is arranged with Arduino and it also calculates the mileage which helps the vehicle user to know about the remaining kilometres of vehicle will pass through based on current speed with the available fuel. The measured fuel levels can be sent through GSM module to the owners of the hiring vehicles by messages through electronic gadgets for their verification purposes. By interfacing GPS module with Arduino board it can show the vehicle's position with help of satellites. The proposed idea of fuel measurement using load cell with Arduino is very cost efficient and easy to use. It may be enhanced with any microcontrollers and can be implemented in all types of vehicles. By using this method petrol bunk frauds can be avoided. This project can be enhanced by interfacing GPS with arduino to track vehicle's location in case of any emergency situations.[5] The increasing corruption in fuel filling process, as well as the increasing vehicle theft, has become a big deal to the society. Thus, this paper has proposed a product that serves beneficiary to both these issues. The corruption in fuel filling process is rectified through fuel level measurement using a load cell. Though there are numerous methods to measure the fuel level including those like mechanical float, optical sensors, ultrasonic etc., the accuracy in measurement is met by the use of load cell involving Arduino Uno microcontroller. Here the precision in measurement is made even in a millilitre of added fuel. The measured output is sent via the global system for mobile communication (GSM) technology to the user mobile so that verifiable record can be created. Thus, a permanent record of filled fuel can be maintained. This would help the owners of transportation network companies to maintain an individual record of their vehicles that are run by their paid drivers. Apart from the level measurement, vehicle theft is overcome by the Global positioning system (GPS) technology. The GPS system fitted to the vehicle would share the accurate location of the vehicle to the registered user. In case of theft, the location of the filling station along with the measured fuel is sent to the registered network through the GSM technology. Thus the paper produces a complete design of the fuel cell that is implemented in a GPS and GSM enabled vehicle. Thus, the proposed systems measures the fuel level added in the petrol bunk and sends the measured value to the display unit on the dashboard and also send an SMS alert to the owner about how much level of fuel is added along with the location. From this design, corruption in the petrol bunk is avoided and owner is alerted with SMS. We implemented this design in real time and it was a success. [11]

\section{SYSTEM ARCHITECTURE}

Presently most of the motor vehicles display the amount of fuel in the fuel tank with the help of traditional meter In daily life we might have experienced the problem of improper measurements of the fuel level in the tank with the existing system Currently the fuel indicator system for the most of the vehicles are analog and they do not show the exact amount of fuel present in the tank. So this problem is taken into consideration in this work for developing the digital fuel indicator system for vehicles which shows exact amount of fuel. The proposed method is a best alternative to fuel measurement techniques to help the users with low cost and requirements. It is an efficient one and also applicable in all types of vehicles. This system can overcome the demerits of existed system and give accurate values to the users. Instead of using fuel sensors to detect the fuel level, here load cell is used. The load cell is attached with base of fuel tank and measures the weight of tank. These values are given to Arduino and it converts weight values into litres. The respective fuel added at petrol bunk and remaining fuel will be displayed in display unit. The vehicle user can get correct quantity of fuel for their paid amount. The LCD display is interfaced with the microcontroller in such a way that when the microcontroller is switched on the current value of fuel is displayed. The microcontroller then checks for the quantity of fuel in the tank and accordingly asks the user to enter the quantity of fuel to be filled. The user can then enter the quantity of fuel to be filled through the keypad which is also interfaced to the microcontroller. After the user gives input time delay is given for the filling of fuel in the tank. After the tank is filled the microcontroller checks for the quantity of 
fuel and if the volume of fuel is not filled properly as specified then the microcontroller is programmed in such a way that the remaining amount of fuel to be filled is displayed in the LCD. The process ends when the volume of fuel filled

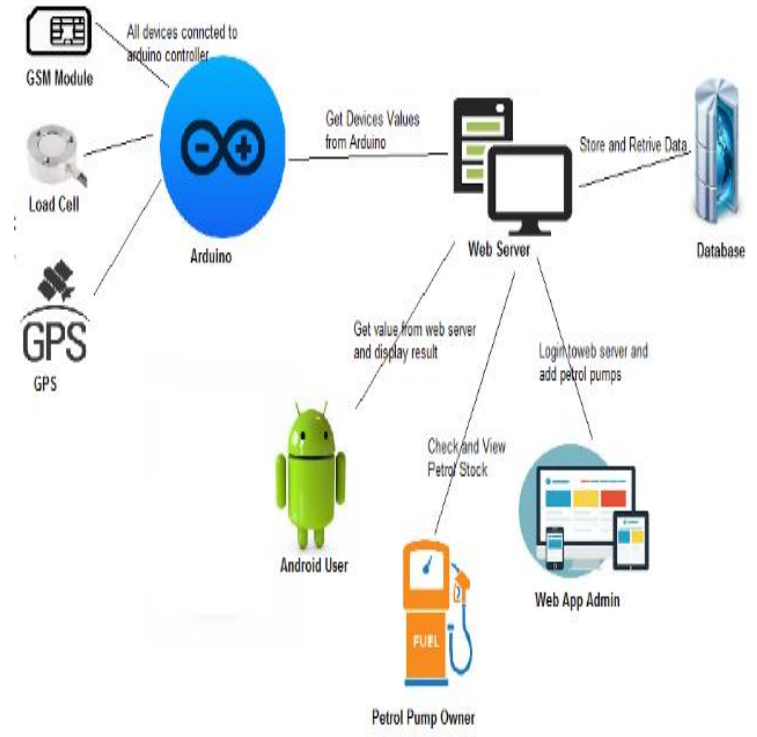

Fig 1: System Architecture

\section{CONCLUSION AND FUTURE WORK}

The System will indicate the fuel level and at the accuracy will be better than the existing systems also how much distance it can travel With the help of the Android Application person will know the nearby petrol pump and the availability of petrol whenever the petrol will get lower than particular level. The measurements are taken so the accuracy level is of percent 95 to 98 . Thusit is an efficient device made by keeping in mind the petroleum thefts at the various petrol pumps at the time of filling of tanks. The existing traditional and the micro controller based float type measurement techniques are far from exact and are on the conservative. A more efficient and reliable sensing technology is the ultrasonic range sensing system with a micro controller which has corrective action code inbuilt that is applied to the fuel sensor signal based on measurements to provide highly accurate measurement of the level of fuel in tank.

\section{ACKNOWLEDGMENTS}

Many thanks to the organizers of the International Journal of Computer Application (IJCA) which has provided an opportunity for authors to publish this paper and to the Ministry of Research and Technology who has funded this research so as to produce a scientific work as well as to the Manado State Polytechnic Institute as well Colleagues who have helped so much that the author can complete this writing.

\section{REFERENCES}

[1] Smart Fuel Theft Detection using Microcontroller ARM7 Nandini Hiremath, Mrunali Kumbhar1, Aakriti Singh Pathania 1 Electronics and Telecommunication Engineering Department, Bharati Vidyapeeth Deemed University College of Engineering, Pune-411043, India. Vinod Patil Faculty, Electronics and Telecommunication Engineering Department, Bharati Vidyapeeth Deemed University College of Engineering, Pune-411043, India. is as per specifications of the user. The LCD display will show us the remaining amount of fuel and the amount of distance it can travel and the Android App will show us the nearby petrol pumps and they are out of petrol or not.

[2] Sandeep S.R1, Adarsh B S2, Rohan Kumar M3, Santosh Kulkarni4, Manjesh C D5 Asst. Professor, Dept. of Electrical and Electronics Engineering, SJBIT, Karnataka, India BE Student, Dept. of Electrical and Electronics Engineering, SJBIT, Karnataka, India Automatic Monitoring of Fuel in Vehicles Using ATMEGA328 Microcontroller.

[3] Giovanni Betta, Member, IEEE, Antonio Pietrosanto and Antonio Scaglione. "A Digital Liquid Level Transducer Based on Optical Fiber".IEEE transactions on Instrumentation and Measurements, VOL. 45, NO. 2, APRIL 1996.

[4] LingtaoMeng, Yunqi Liu, Tingyun Wang. "A Novel Liquid Level Monitoring Sensor System using Fiber Bragg Grating". IET International Conferernce on Smart and Sustainable C City 2013( ICSSC 2013).

[5] FUEL MEASUREMENT USING LOADCELL Raveena A1, Deepa R2 Dept. Of Electronics and Instrumentation Engineering, Bannari Amman Institute of Technology, Tamilnadu, India Associate Professor, Dept. Of Electronics and Instrumentation Engineering, Bannari Amman Institute of Technology, Tamilnadu, India.

[6] Peng Li, YuleiCai, XiaolongShen, Sharon Nabuzaale, Jie Yin and Jiaqiang Li. "An Accurate Detection for Dynamic Liquid Level Based on MIMO Ultrasonic Transducer Array". IEEE Transaction on Instrumentation and Measurement, VOL. 64, NO. 3, MARCH 2015.

[7] By S. M. Khaled Reza, Shah Ahsanuzzaman Md. Tariq and S.M. Mohsin Reza. "Microcontroller Based Automated Water Level Sensing and Controlling: Design and Implementation Issue". Proceedings of the World Congress on Engineering and Computer Science 2010 Vol I WCECS 2010, October 20-22, 2010, San Francisco, USA.

[8] Abhishesh Pal, Roushan Kumar, V. R. Sanal Kumar. "Conceptual Design of an Automatic Fluid Level Controller for Aerospace Applications". 2015 International Conference on Soft-Computing and Networks Security( ICSCN 2015), 25-27 Feb. 2015, Coimbatore, India.

[9] D Ganesh and M. KalyanChakravathi. "Remote Web Based Monitoring and Controlling Of a Nonlinear Process Using Microcontroller". 2014 International Conference on Control, Instrumentation, Communication and Computational Technologies( ICCICCT 2014).

[10] Daniel Obikoya Design, construction, and implementation of a remote fuel-level monitoring system Gbenga .

[11] Load Cell based Fuel Level Measurement using Arduino Uno Microcontroller Aravind R1, Arun Kumar E2, Harisudhan R K3, Karan Raj G4, Udhayakumar G5 Student, Valliammai Engineering College, Kattankulathur, Tamil Nadu Associate Professor, Valliammai Engineering College, Kattankulathur, Tamil Nadu. 